\title{
Effect of Cutting Angle and Knives Type on Some Operational Characteristics for a Locally Manufactured Palm Pruning Motorized Vibration Cutter
}

\author{
Abdulrazak A. Jasim ${ }^{1}$, Moayad R. Abbood ${ }^{2}$, Shamil M. Abbood ${ }^{2}$ \\ Prof.PhD. Prof.PhD.Asst.Lect. \\ ${ }^{I}$ Dept.of Agricultural Machines and Equipment, College of Agriculture, University of Baghdad \\ ${ }^{2}$ Dep. of Horticulture and Landscape Gardening College of Agriculture, University of Baghdad
}

\begin{abstract}
The experiment was conducted to evaluate the effect of cutting angles and knife type on some operations characteristics for a locally palm pruning motorizedvibration cutter. An equipment was fabricated to use a vibration motion to operate the cutting knife to cut the base of date palm fronds around the date palm tree trunk. Three cutting angles included $45^{\circ}, 60^{\circ}$ and $90^{\circ}$ with three locally manufactured knives included $A, B$ and $C$ types were used in this study. Time of cutting one frond, time of cutting three rows of fronds, level of cutting difference, productivity and efficiency was measured in this experiment. Randomized Complete block design with three replication was used in this experiment. Least significant differences (L.S.D.) under 0.05 level was used to compare the mean of treatment. The results can be summarized as follow: $45^{\circ}$ cutting angle gave a lower one frond cutting time, three rows cutting time and differences of surface cutting level amounted to $2.65 \mathrm{sec} .1 .74 \mathrm{~min} ., 5.28 \mathrm{~mm} .45^{\circ}$ and $60^{\circ}$ cutting angle got higher productivity stood 8.01 palm $/ \mathrm{h}$ for both angles. Type (B) knife got lowest cutting time stood $3.22 \mathrm{sec}$. and higher productivity stood 8.80 palm $/ h$, while type A knife got a lowest ofthree rows of fronds and differences of surface cutting level stood $1.68 \mathrm{~min} .5 .28 \mathrm{~mm}$. also type A knife got higher efficiency amounted to $87.67 \%$. The interaction between cutting angle and knife type has significant effect on all properties. Using vibration motorizedcutter forcutting date palm fronds successfully done.
\end{abstract}

Keywords: cutting angle, knives type, frond cutting, vibration, noise, productivity and efficiency

\section{Introduction}

The date fruit has high energy food for both people and livestock. Since ancient times .dates are the best resource to insure food security during food shortage and crises (Ahmed et al,2012). Many of field operations involving the date palm include manual work at the crown of the tree i.e. These operation take place at various time during the year (Akyurt et al,2002).The date palm tree grows about $30 \mathrm{~cm}$ a year and it may reach a high of $35 \mathrm{~m}$ in age about 100 years,(Morton,1987). Pruning is one of the important operation practices to remove the palm dry and dead levies and leave bases.This operation eliminates insects and spreading of diseases , also make the palm trunk graded to make it easier to climb, the operation can be done manually or mechanically by using a hydraulic lift or ladders (Ahmed and Andrzeg,2012 and Owda,2014).pruning is most difficult operationand itneed more human energy specially when used a traditional tools like knives and saws( Jelani,1998). The knife shape and type has significant factor to cut the base of palm fronds(Person, 1987 and Ahmed et al.2000). Also, the angle of cutting play a big role to do the cutting operation (jelani,etal, 1998).According to the importance of mechanical pruning by using different type of knives under the different cutting angle this study was conducted.

\section{Materials And Methods}

The experiment was conducted for testing three types of locally manufacturing A, B and $\mathbf{C}$ under cutting angle knives degrees included, $45^{\circ}, 60^{\circ}$ and $90^{\circ}$ were used in this study. Assembly motorized vibration generator with bevel gear case used to vibrate the knife in 3000-5000 rpm and movement knife stroke about 1.6 $\mathrm{cm}$, (fig.1).Knives was manufacturing by hot forgein local workshop using the (ASTM579) alloy, this material consider a high a durability. Also all knives have $2 \mathrm{~mm}$ thickness and $0.5 \mathrm{~mm}$ sharp edge.

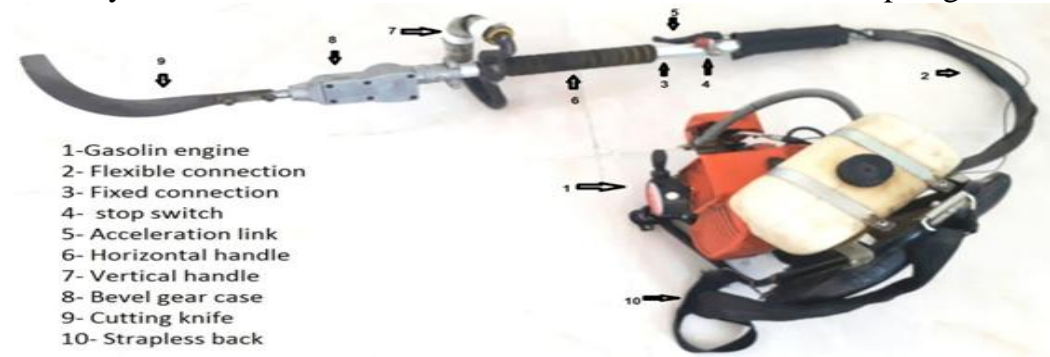

Fig .1 vibration motorized cutter 
Knives were forged by usingovenat $\mathbf{7 9 0} \mathbf{C}^{\circ}$ for $30 \mathrm{~min}$ then doing water cooling to give them good hardness, after that, tested the knife samples hardness by using Rockwell test, it is stood 65 HR.(fig 2).One frond cutting time, one palm fronds cutting time, surface level of cutting, productivity and efficiency were measured in this experiment.Randomized complete block design (RCBD) with three replications was used in this study. Least significant differences (L.S.D) under 0.05 level used to compare the mean of treatment.

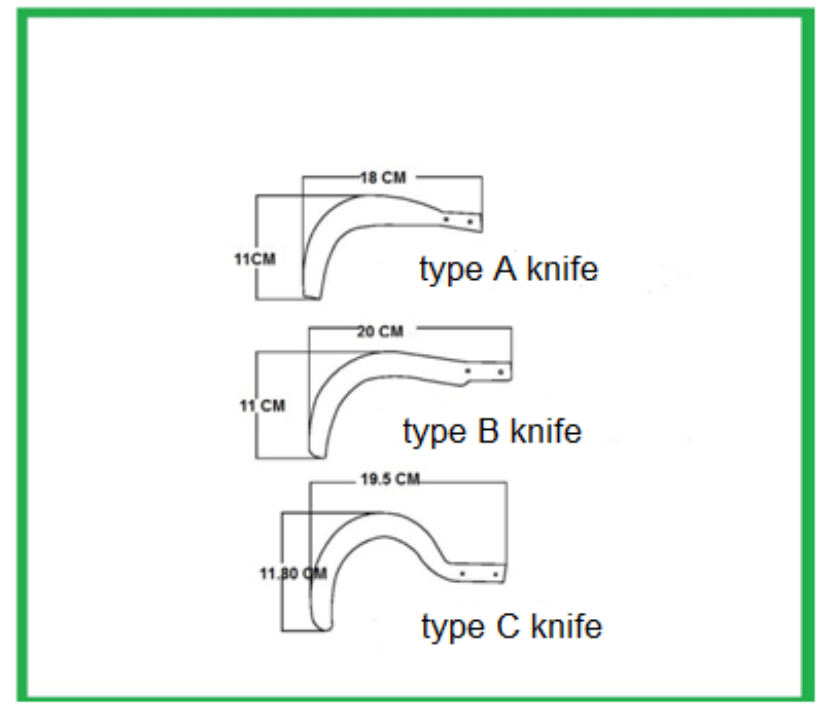

Fig. 2 types of knives

\subsection{Studied properties}

2.2.1. Timeof cutting one frond.

Time measured by using stopwatch when the worker starts cutting frond base and registers the actual time.

2.2.2 Time of cutting three rows of palm frond min.

Time measured by using same method in 2.2.1 .

\subsubsection{Surface level cutting.}

It was measured the different in cutting surface level by using a filler gage and metalruler (mm).

\subsection{4 - Productivity.}

It was measured by calculate the total time of cutting three rows of fronds including the lost time for rest and moving in the field also the time of refuel the implement of fuel and maintenance in palm per hour (palm.h).

\subsection{5 - Field efficiency}

Field efficiency was measured by using the following question which proposedby( hunt, 1980)

$\mathbf{F e}=\mathbf{P}_{\mathrm{p}} / \mathbf{P}_{\mathbf{t}} \mathbf{x 1 0 0}$

Whereas:Fe $=$ Field Efficiency $\%$.

$\mathbf{P}_{\mathbf{p}}=$ Practical productivityPalm/ $\mathrm{h}$.

$\mathbf{P}_{\mathbf{t}}=$ Theoretical productivity $\mathrm{Palm} / \mathrm{h}$.

3.1 Time of cutting one frond, ( $\mathrm{sec})$.

\section{Results And Discussion}

Table 1 shows the effect of cutting angle and knife type on time for one front cutting, $45^{\circ}$ cutting angle showed the superiority in the time of cutting one frond stood $2.65 \mathrm{sec}$ compared with $60^{\circ}$ and $90^{\circ}$ they got 3.87 and $4.15 \mathrm{sec}$ respectively..These results agreed with the results which proposed by (Jelani, 1998).Type A knife got the less cutting time stood $2.93 \mathrm{sec}$ comparing with $\mathbf{B}$ and $\mathbf{C}$ type the overlap between the $45^{\circ}$ cutting angle and $\mathbf{B}$ type of knife obtained the lowest cutting time amount $2.03 \mathrm{sec}$. and the highest cutting time achieved $4.89 \mathrm{sec}$. for the overlap of $90^{\circ}$ cutting angle and $\mathbf{C}$ type knife.

Table 1 effects of cutting angle and type of knife I time of cutting one frond sec.

\begin{tabular}{|c|c|c|c|c|}
\hline \multirow{2}{*}{ Cutting angle } & \multicolumn{3}{|c|}{ Type of knife } & \multirow[t]{2}{*}{ Average } \\
\hline & A & B & $\mathrm{C}$ & \\
\hline $45^{\circ}$ & 2.06 & 2.03 & 3.86 & 2.65 \\
\hline $60^{\circ}$ & 3.56 & 3.78 & 4.28 & 3.87 \\
\hline $90^{\circ}$ & 3.71 & 3.87 & 4.89 & 4.15 \\
\hline L.S.D & \multicolumn{3}{|l|}{0.186} & 0.097 \\
\hline Average & 2.93 & 3.22 & 4.34 & \\
\hline L.S.D & \multicolumn{3}{|c|}{0.118} & \\
\hline
\end{tabular}




\subsection{Time of cutting three rows of palm frond, ( $\mathrm{min})$.}

Table 2 shows the effect of cutting angle and type of knife on time of cutting three rows of date palm fronds, $90^{\circ}$ cutting angle showed a significanteffect on the time of cutting it was got a highest time stood 2.72 min ,while no effect between A and B knife type they got $2.40,2.43$ min respectively,this results agree with the results of (Jelani,et al,1998). The overlap between $45^{\circ}$ and the A type of knife obtained the Lowest time of cutting amounted to $1.68 \mathrm{~min}$ and the highest cutting time achieved $4.40 \mathrm{~min}$ for the $90^{\circ}$ cutting angle with a $\mathrm{C}$ type of knife.

Table 2 effects of cutting angle and type of knife on time of cutting threefronds rows (min)

\begin{tabular}{|c|c|c|c|c|}
\hline \multirow{2}{*}{ Cutting angle } & \multicolumn{3}{|c|}{ Type of knife } & \multirow[t]{2}{*}{ Average } \\
\hline & A & B & $\mathrm{C}$ & \\
\hline $45^{\circ}$ & 1.68 & 1.69 & 3.83 & 2.40 \\
\hline $60^{\circ}$ & 1.69 & 1.69 & 3.91 & 2.43 \\
\hline $90^{\circ}$ & 1.86 & 1.91 & 4.40 & 2.72 \\
\hline L.S.D & \multicolumn{3}{|c|}{0.173} & 0.114 \\
\hline Average & 1.74 & 1.76 & 4.04 & \\
\hline L.S.D & \multicolumn{3}{|c|}{0.291} & \\
\hline
\end{tabular}

\subsection{Surface level cutting, $(\mathrm{mm})$.}

Table 3 showed the effect of cutting angle and knife type on surface cutting level. 45 cutting angle showed the superiority in the difference on level surface of frond cutting amounted to $5.28 \mathrm{~mm}$ compared with 90 cutting angle which got $6.17 \mathrm{~mm}$. Type ( A) knife got a lowest difference in surface level stood $5.28 \mathrm{~mm}$. The overlap between cutting angle and type of knife obtained the lowest difference of surface `cutting level amounted to $5.16 \mathrm{~mm}$.

Table 3 effects of cutting angle and type of knife surface cutting level (mm).

\begin{tabular}{|l|l|l|l|l|}
\hline \multirow{2}{*}{ Cutting angle } & \multicolumn{3}{|c|}{ Type of knife } & \multirow{2}{*}{ Average } \\
\cline { 2 - 4 } & A & B & C & \\
\hline $45^{\circ}$ & 5.16 & 5.29 & 5.41 & 5.28 \\
\hline $60^{\circ}$ & 5.41 & 5.46 & 5.69 & 5.61 \\
\hline $90^{\circ}$ & 6.40 & 5.40 & 6.68 & 6.17 \\
\hline L.S.D & 0.193 & \multicolumn{2}{|c|}{0.111} & 0.129 \\
\hline Average & 5.65 & 5.92 & \\
\hline L.S.D & \multicolumn{4}{|c|}{0.11} \\
\hline
\end{tabular}

\section{4- Productivity, (palm/h).}

Table (4) showed the effect of cutting angle on one palm cutting with tree rows of fronds, there is not difference in result between 45 and 60 cutting angle amounted to $8.01 \mathrm{palm} / \mathrm{h}$. for both angles ,but the results showed a significant effect in used 90 cutting angle was stood $7.62 \mathrm{palm} / \mathrm{h}$. Using (B) type of knives got a higher productivity stood $8.80 \mathrm{palm} / \mathrm{h}$. compare with 45 and 90 cutting angles which they got 8.77 and 6.09 $\mathrm{palm} / \mathrm{h}$. respectively. The overlap between cutting angle and knives type obtained the highest productivity amounted to $8.91 \mathrm{palm} / \mathrm{h}$, and the lowest productivity achieved $5.75 \mathrm{palm} / \mathrm{h}$.

Table 4.the effect of the cutting angle and the knives type on equipment productivity palm/h.

\begin{tabular}{|l|l|l|l|l|}
\hline \multirow{2}{*}{ Cutting angle } & \multicolumn{3}{|c|}{ Type of knife } & \multirow{2}{*}{ Average } \\
\cline { 2 - 4 } & $\mathrm{A}$ & $\mathrm{B}$ & $\mathrm{C}$ & \\
\hline $45^{\circ}$ & 8.89 & 8.91 & 6.25 & 8.01 \\
\hline $60^{\circ}$ & 8.85 & 8.97 & 6.23 & 8.01 \\
\hline $90^{\circ}$ & 8.57 & 8.51 & 5.75 & 7.62 \\
\hline L.S.D & \multicolumn{3}{|c|}{0.271} & 0.215 \\
\hline Average & 8.77 & 8.80 & 6.09 & \\
\hline L.S.D & \multicolumn{4}{|c|}{0.135} \\
\hline
\end{tabular}

3.5. Field efficiency, $(\%)$.

The result in table( 5 ) showed the significant effect of used 45 cutting angle on field efficiency it got $80.23 \%$ compared with 60 and 90 angles which they got 79.51 and $75.51 \%$ respectively. Type (A) knife got a higher efficiency amounted to $87.67 \%$ compare with (B) and (C) type which they got 78.36 and $60.90 \%$ respectively. Theresults in table 5 showed the interference between cutting angles and knives type ,45 cutting angle and (B) knife type got higher efficiency stood $89.10 \%$ and the lower efficiency in interference of 90 cutting angle and type (C) knife which got $57.85 \%$. The reason may be for a speed of cutting for 45,60 angle and (B) knife type are more easily than 90 and (C) type of knives. 
Table 5.Effect of cutting angles and knives types on field efficiency\%

\begin{tabular}{|c|c|c|c|c|}
\hline \multirow[t]{2}{*}{ Cutting angle } & \multicolumn{3}{|c|}{ Type of knife } & \multirow[t]{2}{*}{ Average } \\
\hline & $\mathrm{A}$ & $\mathrm{B}$ & $\mathrm{C}$ & \\
\hline $45^{\circ}$ & 89.05 & 89.10 & 62.55 & 80.23 \\
\hline $60^{\circ}$ & 88.55 & 87.70 & 62.30 & 79.51 \\
\hline $90^{\circ}$ & 86.00 & 82.70 & 57.85 & 75.51 \\
\hline L.S.D & \multicolumn{3}{|c|}{0.324} & \\
\hline Average & 87.76 & 87.36 & 60.90 & \\
\hline L.S.D & \multicolumn{3}{|c|}{1.747} & \\
\hline
\end{tabular}

\section{Conclusion and Recommendation}

Using different cutting angles with three types of cutting knife in motorizedvibration cutter used to cut the date palm fronds is successfully done.Theabove results are showedclearly that increase the cutting angle from $45^{\circ}$ to $90^{\circ}$ led to increase the time of cutting onefrond, three rows of fronds cutting time and difference of surfacecuttinglevel, also decrease the productivity and efficiency. Therefore, we recommend using $45^{\circ}$ cutting angle with one of (A) and(B) type of knife which gave the best time of cutting, high productivity and efficiency

\section{References}

[1] Ahmed, D and A.Borowy, (2012). Cultivation of date palm in Iraq.AnnalesUniversitatisMariae Curie- sklodowska Lublin- polonia. Vol.xxII (1) Section EEE.

[2] Ahmad, D. S.K Roy and A.R. Jaelani,( 2000). Evaluation of Design Parameters of Cycle Cutter and Claw Cutter for Cutting Oil Palm Frond. AMA Journal. 31(2): $55-60$.

[3] Jelani, A, R,; D. Ahmad;H. Ahmad;Y.Azmi and J.Johari, (1998).Force and Energy Requirements for Cutting Oil Palm Frond .Jornal of Oil Palm Research Vol.10 .No.2.pp.10-24.

[4] Jelani, A. R.,(2008). Cantas TM - A tool for the Efficient Harvesting of Oil Palm Fresh Fruit Bunches. Journal of Oil Palm Research vol.20p.548-558

[5] Morton, J., (1987); "Date Phoenix Dactylifera," in: Fruits Of Warm Climates, Miami, Creative Resource Systems, Inc., Winterville, NC,http://www.hort.purdue.edu/newcrop/morton/ index. html (last updated: 4/2/1999).

[6] Akyurt M., E Rehbini., H.Bogis, A.A. Aljanabi (2002). A survey of mechanization efforts on date palm crown operations .the $6^{\text {th }}$ Saudia engineering conference, KFUPM, Daharan, December, 2002.

[7] Owda, A., (2014) .Date palm tree, cultivation, service, technical care and manufacturing. Educational Essa center. Kinkom of Bahrain

[8] Persson, S. (1987). Mechanics of Plant Cutting Material.Michigan. American Society ofAgricultural Engineers. 